\title{
Estimating river discharge from earth observation measurements of river surface hydraulic variables
}

\author{
J. Negrel, P. Kosuth, and N. Bercher \\ Cemagref, UMR TETIS-500 rue Jean-François Breton-34093 Montpellier Cedex5, France
}

Received: 23 July 2010 - Published in Hydrol. Earth Syst. Sci. Discuss.: 8 October 2010

Revised: 17 May 2011 - Accepted: 15 June 2011 - Published: 29 June 2011

\begin{abstract}
River discharge is a key variable for quantifying the water cycle, its fluxes and stocks at different scales. These scales range from a local scale for the efficient management of water resources to a global scale for the monitoring of climate change. Therefore, developing Earth observation (EO) techniques for the measurement or estimation of river discharge poses a major challenge. A key question deals with the possibility of deriving river discharge values from EO surface variables (width, level, slope, and velocity are the only such variables accessible through EO) without any in situ measurement. Based on a literature study and original investigations, this study explores the possibilities of estimating river discharge from water surface variables.

The proposed method relies on limiting assumptions to simplify river flow equations to obtain the values of the hydraulic parameters at a given river station without using ground measurements. Once the hydraulic parameters are identified, the method allows the estimation of the river discharge corresponding to a set of surface measurements of hydraulic variables.
\end{abstract}

\section{Introduction}

Traditionally, river discharge is estimated using frequent in situ measurements. Periodically, the water flow velocity, the channel cross-section surface and the water level are recorded at gauging stations. Several stations are located along the river basin to monitor the entire basin. These instantaneous pictures of the river configuration are used to build or adjust rating curves linking the water level to the discharge (Franchini et al., 1999). Hence, the continuous measurement of these levels allows the estimation of the dis-

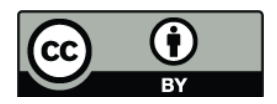

Correspondence to: J. Negrel (jean.negrel@teledetection.fr) charge at a specific gauging station. During the past two decades, the Acoustic Doppler Current Profiler (ADCP) has considerably eased and increased the accuracy of river monitoring (Gordon, 1989; Morlock, 1996; Oberg and Mueller, 2007). However, gathering reliable, long-term and consistent information on river discharges worldwide or on large trans-boundary river basins is an extremely complex task, if it is indeed ever achievable. Indeed, Hydrologic Services in different countries have heterogeneous acquisition strategies and data policies. This situation leads primarily to issues of reference levels (Kosuth et al., 2006), to data transmission delays and to unsynchronised measurements periodicity. Therefore, the development of Earth Observation (EO) techniques for the measurement or estimation of river discharges poses a major challenge.

Although in situ data acquisition is and will remain a keystone of hydrological monitoring and hydrological knowledge, an important question addresses the possibility of deriving river discharge values without any in situ measurement, based exclusively on river surface variables accessible through EO techniques, namely river width, level, surface slope and surface velocity. Such a method would allow a global monitoring of river discharges worldwide, and it would usefully complement high-accuracy in situ measurement networks.

The problem can be approached in terms of two separate questions:

1. To what extent can EO techniques provide reliable measurements of river surface variables, and what is the accuracy associated with these techniques?

2. How can we derive discharge estimates from these surface variables?

The possibility of using EO techniques to measure river surface variables has been developed and discussed in numerous papers, from optical or SAR imagery for river width

Published by Copernicus Publications on behalf of the European Geosciences Union. 
(Zhang et al., 2004; Xu et al., 2004; Smith et al., 1995, 1996) to RADAR or LIDAR altimetry for river level (Coe and Birkett, 2004; Alsdorf et al., 2001; Costa et al., 2000), and from RADAR across-track interferometry for surface slopes (LeFavour and Alsdorf, 2005) to along-track interferometry for surface velocity (Thompson et al., 1994; Macklin et al., 2004; Romeiser et al., 2007). The scientific and technological progress achieved in these domains has been very rapid and has mobilised large, combined efforts by the scientific community, space agencies and industry (Alsdorf et al., 2007). However, the accuracy of these data is still limited. Improvement of the accuracy of the data is a major challenge. The accuracy of the data should be carefully considered in any effort to estimate river discharge.

Assuming that these river surface variables can be measured by EO with a satisfactory amount of accuracy, we can concentrate our efforts on the second question associated with this problem. A method has been developed to estimate river discharge from these variables. The goal of this paper is to present this method of using remotely sensed hydrological variables to estimate river discharge and to discuss the results of our analyses.

\section{Presentation of a statistical approach}

A large number of discharge estimation methods based on EO techniques have been developed, Sun et al. (2010) presented a broad review of the different methods. All of the methods reviewed have led to interesting and encouraging results. However, most of the methods were limited by the need for ground measurements to calibrate the algorithm, or at least by the requirement for information on one or more hydraulic parameters, for example the roughness coefficient in the case of (Durand et al., 2010).

One statistically-based approach (Bjerklie et al., 2003, 2005) focuses on the ability to estimate river discharge all over the globe without needing ground measurements, except for the initial database used to calibrate the models. This method relies on different combinations of surface variables extracted from the Manning-Strickler equation and from the flux expression for river discharge. Using the relationships between hydraulic variables (Bjerklie et al., 2005) have obtained the following five expressions for river discharge:

$$
\begin{aligned}
& Q=c_{1} W^{a} Y^{b} I_{\mathrm{s}}^{d} \\
& Q=c_{2} W^{e} V^{f} I_{\mathrm{s}}^{g} \\
& Q=c_{3} W^{e} V^{f} \\
& Q=c_{4} W_{\mathrm{m}}^{g} Y_{\mathrm{m}}^{h} I_{\mathrm{s}}^{i} Y^{j} \\
& Q=c_{5} W_{\mathrm{m}}^{k} Y_{\mathrm{m}}^{l} I_{\mathrm{s}}^{m} L^{n}
\end{aligned}
$$

where $c_{k}, k=1 \ldots 5$ are coefficients, $Q$ is the river discharge, $W$ the river width, $Y$ the river depth, $V$ the mean velocity and $I_{\mathrm{S}}$ the water surface slope, $W_{\mathrm{m}}$ and $Y_{\mathrm{m}}$ represent the full-bank values of width and depth, respectively.
The discharge is therefore expressed as the product of a $c_{k}$ parameter and some hydraulic variables raised to constant powers. The coefficients and the power constants of the hydraulic variables in these five expressions have been fitted using in situ measurements obtained from a large dataset including information on many different rivers (mainly from North America and New Zealand).

This method appears to give a satisfactory mean estimation of global discharge (with a mean error within a $10 \%$ range) using the whole dataset. In theory, therefore, the method is applicable to any river in the world.

However, two main problems arise:

1. Two of the five expressions $(1,4)$ rely on data on the depth of the river. But this hydraulic variable cannot be measured from space because radar techniques cannot penetrate water and because ground-penetrating radar needs to be close to the surface (Melcher et al., 2002). Moreover, lidar techniques are limited to shallow (less than 6 or $7 \mathrm{~m}$ ) and non-turbulent water (Wang and Philpot, 2007).

2. Even if the method represents a truly accurate statistical estimate of the discharge, this accuracy does not imply that the method is able to estimate a unique measurement at a specific river station.

In order to verify this latter assumption, we applied these estimation methods to a dataset of ADCP measurements obtained from the Amazon basin and to a simulated dataset (Sects. 3.3, 4.4). All of the applications of those equations were made using the parametrisation recommended in (Bjerklie et al., 2005). We deliberately did not recalibrate the equations. Such recalibration would have required discharge information. That approach was therefore not consistent with our goal: estimate the discharge blindly.

Nevertheless, even if the parameters were not calibrated for the rivers used, we reached conclusions quite similar to those detailed in (Bjerklie et al., 2003, 2005). More detailed results and a comparison with our proposed model are discussed in Sect. 4.4.

However, lack of information about the water depth remains a problem, because such information is not available from $\mathrm{EO}$ techniques nowadays.

\section{Proposed method}

\subsection{Rationale for the proposed method}

The method we propose is based on the 3 following steps:

1. A set of limiting assumptions simplify the fundamental Saint-Venant hydrodynamic equations leads to two expressions for the discharge in a river section as a function only of the surface variables and hydraulic parameters. 
2. The flow rate expression and the Strickler formulation of the linear energy slope yield two estimates of the river discharge, namely $Q_{1}$ and $Q_{2}$. These estimates must be consistent over the full range of the hydraulic regime. Therefore, the problem of the determination of the values of the hydraulic parameters can be formulated in terms of the minimisation of an error criterion involving the two estimates of the discharge over a set of surface variables measured at different stages of the river cycle.

3. Once the hydraulic parameters have been determined, the two consistent estimates $Q_{1}$ and $Q_{2}$ can be quantified and merged into a unique discharge estimate $Q^{*}$, by using (for example) the mean of the two estimates of the same discharge.

The measurable surface variables are width $W$, water elevation $Z$, surface velocity $V_{\mathrm{s}}$ and surface slope $I_{\mathrm{s}}$; the hydraulic parameters are the hydraulic radius $R_{\mathrm{h}}$, the mean river bed elevation $Z_{\mathrm{b}}$, the bottom slope $I_{\mathrm{b}}$, the Strickler roughness coefficient $K$ and the ratio between surface velocity and mean velocity $\alpha$.

The hydraulic radius is defined as $R_{\mathrm{h}}=A / P$, where $A$ is the flow area and $P$ the wetted perimeter. We assumed the flow area to be simplified as a rectangular cross-section. It could therefore be expressed as the product of the river width $W$ and the river mean depth $Y$. We also assumed a wide and shallow river configuration (on the Amazon River, on which we worked, $W / Y \approx 50$ ). As $W \gg Y$, the wetted perimeter is equivalent to the river width $P=W+2 \cdot Y \approx W$. The hydraulic radius is now represented as:

$$
\begin{aligned}
R_{\mathrm{h}} & =\frac{A}{P} \\
& \approx \frac{W \cdot Y}{W} \\
& \approx Y=\left(Z-Z_{\mathrm{b}}\right)
\end{aligned}
$$

The discharge and related hydraulic variables are not expected to vary significantly on a day-to-day basis, in the absence of exceptional events such as dam release or flash flooding. We can reasonably expect that in the near future, satellite technical improvements will provide the possibility of measuring these variables within an appropriate time window.

These considerations lead to the formulation of six limiting assumptions that serve to simplify the expression of the discharge:

A1 Steady flow configuration at each measurement

A2 Rectangular cross-section of a wide and shallow river

A3 Strickler formulation of the linear energy slope $S$

$$
S=\frac{Q^{2}}{K^{2} \cdot A^{2} \cdot R_{\mathrm{h}}^{4 / 3}}
$$

A4 Strickler coefficient $K$ constant in time for each station

A5 $\alpha$ ratio constant in time and space.

A6 Uniform flow configuration, which leads to the equality between linear energy slope $S$, river surface slope $I_{\mathrm{S}}$ (the only slope measurable) and river bed slope $I_{\mathrm{b}}: S=I_{\mathrm{s}}=$ $I_{\mathrm{b}}$.

\subsection{Development of the method}

The river discharge can be expressed using two different expressions:

- the flow rate expression

$$
\begin{aligned}
Q_{1} & =V \cdot A \\
& \approx \alpha \cdot V_{\mathrm{s}} \cdot W \cdot\left(Z-Z_{\mathrm{b}}\right)
\end{aligned}
$$

- and the Strickler relationship.

$$
\begin{aligned}
Q_{2} & =S^{1 / 2} \cdot K \cdot A \cdot R_{\mathrm{h}}^{2 / 3} \\
& \approx I_{\mathrm{s}}^{1 / 2} \cdot K \cdot W \cdot\left(Z-Z_{\mathrm{b}}\right)^{5 / 3}
\end{aligned}
$$

As these two discharge expressions must be consistent, Eqs. (8) and (9) must be equal:

$\alpha \cdot V_{\mathrm{s}} \cdot W \cdot\left(Z-Z_{\mathrm{b}}\right)=I_{\mathrm{s}}^{1 / 2} \cdot K \cdot W \cdot\left(Z-Z_{\mathrm{b}}\right)^{5 / 3}$

This result produces the following expression for the water elevation:

$$
\begin{array}{r}
Z=Z_{\mathrm{b}}+\frac{\alpha^{3 / 2}}{K^{3 / 2}} \cdot \frac{V_{\mathrm{s}}^{3 / 2}}{I_{\mathrm{s}}^{3 / 4}} \\
Z=\beta \cdot x+Z_{\mathrm{b}}
\end{array}
$$

with $\beta=\frac{\alpha^{3 / 2}}{K^{3 / 2}}$ and $x=\frac{V_{\mathrm{s}}^{3 / 2}}{I_{\mathrm{s}}^{3 / 4}}$.

The water level $Z$ is now given as a linear equation in two unknown parameters ( $\beta$ and $Z_{\mathrm{b}}$ ) and a variable $x$ that represents the combination of the measured surface variables $V_{\mathrm{s}}$ and $I_{\mathrm{s}}$.

Based on a set of surface variable measurements $\left(Z_{i}, V_{\mathrm{s} i}, I_{\mathrm{s} i}\right)_{(i=1 \cdots N)}$ at different dates and phases of the hydrological cycle, the linear expression of Eq. (11) is used to estimate the unknown parameters $Z_{\mathrm{b}}$ and $\beta$. This estimation is performed using the linear least squares method to minimise a criterion $J$ that represents the root mean square error of the water level estimator:

$$
J=\sum_{i=1}^{N}\left[Z_{i}-Z\left(V_{\mathrm{s} i}, I_{\mathrm{s} i}\right)\right]^{2}=\sum_{i=1}^{N}\left[Z_{i}-Z_{\mathrm{b}}-\beta \cdot x_{i}\right]^{2}
$$


The problem associated with this formulation of the error criterion, Eq. (14), is the impossibility of estimating the $\alpha$ parameter and the Strickler coefficient $K$ from the estimated parameter $\beta$.

The $\alpha$ parameter is generally considered to be constant. Its value is approximately 0.85 for a small river and 0.90 for a wide river (Rantz, 1982; Costa et al., 2000). Moreover, we led an analysis, using our ADCP measurements from the different Amazon gauging stations, to verify the validity of this fixed value of $\alpha$. The mean value of $\alpha=0.9$ has been checked using the entire dataset as well as individual gauging stations. The fitted value has a standard deviation of 0.04 for the Manacapuru station and a standard deviation of 0.06 for the Obidos station. We therefore decided to set this value constant. It then became possible to calculate the Strickler coefficient $K$ easily from the $\beta$ estimated parameter: $K=\frac{\alpha}{\beta^{2 / 3}}$.

The resolution of the parameters $Z_{\mathrm{b}}$ and $\beta$ was achieved by solving the simple linear least squares problem using matrix inversion:

$\hat{B}=\left(X^{T} \cdot X\right)^{-1} \cdot X^{T} \cdot Z$

with $X=\left(\begin{array}{ll}x & 1\end{array}\right)$ and $\hat{B}=\left(\begin{array}{c}\beta \\ Z_{\mathrm{b}}\end{array}\right)$.

\subsection{Datasets}

As detailed in the Introduction, no existing remote sensing measurements are sufficiently accurate to allow this method to be tested. Moreover, the steady-flow assumption requires concurrent measurements of all the surface variables, or at least in a short enough time window. As explained in Sect. 3.1, we can expect a future satellite or satellite train to allow measurements that meet these requirements.

In absence of such measurements, the method was tested on datasets taken at several gauging stations in the Amazon basin $\left(\mathrm{HyBAm}^{1}, \mathrm{ANA}^{2}-\mathrm{IRD}^{3}\right.$, Project). The gauging station records the water elevation on a daily basis. Therefore, we can easily have the water level associated with the ADCP campaigns in a short time lapse. To apply the method, the datasets were constructed directly from ADCP measurements (Callède et al., 2000) for the surface velocities and surface width, whereas water level and longitudinal river slope were provided by the in situ monitoring of levelled gauging stations and relevant techniques for deriving the longitudinal profile and slope (Bercher, 2008). The surface slope estimation method was initially developed to interpolate the water elevation between levelled gauging stations. It fits a 4th order polynomial using four gauging station measurements and a constraint on the second derivative of the polynomial. This

\footnotetext{
${ }^{1}$ http://www.ore-hybam.org

${ }^{2}$ http://www.ana.gov.br

${ }^{3}$ http://www.ird.fr/
}

Table 1. Set of measurements at the Manacapuru gauging station.

\begin{tabular}{cccccc}
\hline & $Q\left(\mathrm{~m}^{3} \mathrm{~s}^{-1}\right)$ & $L(\mathrm{~m})$ & $Z_{\mathrm{S}}(\mathrm{m})$ & $V_{\mathrm{S}}\left(\mathrm{m} \mathrm{s}^{-1}\right)$ & $I_{\mathrm{S}}\left(\mathrm{m} \mathrm{m}^{-1}\right)$ \\
\hline 1 & 115304 & 3180 & 20.14 & 1.48 & $2.04 \times 10^{-5}$ \\
2 & 84949 & 3216 & 16.83 & 1.30 & $1.97 \times 10^{-5}$ \\
3 & 51908 & 3074 & 10.68 & 1.07 & $2.18 \times 10^{-5}$ \\
4 & 138744 & 3108 & 22.93 & 1.66 & $2.23 \times 10^{-5}$ \\
5 & 61984 & 3210 & 14.09 & 1.08 & $1.55 \times 10^{-5}$ \\
6 & 115653 & 3241 & 19.87 & 1.56 & $2.43 \times 10^{-5}$ \\
7 & 56227 & 3219 & 11.29 & 0.97 & $1.43 \times 10^{-5}$ \\
8 & 116228 & 3140 & 21.23 & 1.52 & $2.12 \times 10^{-5}$ \\
9 & 51973 & 2901 & 11.47 & 1.03 & $1.75 \times 10^{-5}$ \\
10 & 90361 & 3208 & 16.71 & 1.35 & $2.16 \times 10^{-5}$ \\
11 & 113447 & 3246 & 19.82 & 1.50 & $2.22 \times 10^{-5}$ \\
12 & 134494 & 3255 & 22.45 & 1.61 & $2.21 \times 10^{-5}$ \\
13 & 117406 & 3250 & 20.91 & 1.45 & $2.09 \times 10^{-5}$ \\
14 & 62354 & 3157 & 12.53 & 1.14 & $2.08 \times 10^{-5}$ \\
15 & 104262 & 3236 & 18.39 & 1.48 & $2.19 \times 10^{-5}$ \\
16 & 142430 & 3154 & 23.41 & 1.71 & $2.18 \times 10^{-5}$ \\
17 & 108003 & 3288 & 18.55 & 1.52 & $2.43 \times 10^{-5}$ \\
18 & 73457 & 3187 & 14.23 & 1.25 & $2.34 \times 10^{-5}$ \\
19 & 109884 & 3456 & 19.93 & 1.47 & $2.16 \times 10^{-5}$ \\
20 & 126337 & 3276 & 22.65 & 1.55 & $2.11 \times 10^{-5}$ \\
\hline
\end{tabular}

method is based on the strictly decreasing and smooth curvature river profile, at a given time, and the absence of strong local variation (water falls, for example). We simply differentiate the polynomial at the given gauging station to get the surface slope.

Several datasets were used. The first datasets represent several gauging stations in the Amazon basin. We initially selected six gauging stations: Manacapuru, Paricatuba, Jatuarana, Parintins, Obidos and Borba. But we concentrated our efforts on the data from only two stations:

$$
\text { - Manacapuru (Table 1) }
$$

These two stations gave us the highest number of measurements along with the best-quality acquisitions (ADCP data do not contain too many missing or aberrant values). Jatuarana, Paricatuba and Borba only have five different ADCP measurements date which is clearly not enough to calibrate our parameters. Parintins ADCP measurements contain too much missing data, probably caused by the sediment load disrupting the ADCP.

The second dataset represents simulated data generated by SIC, a 1-D hydrodynamic model, described in (Baume et al., 2005) and validated against ASCE tests (Contractor and Schuurmans, 1993) and ground data. This model generates series of hydraulic variables by solving the Saint-Venant equations under steady-flow conditions with a given incoming discharge and downstream water level condition. The only hydraulic variable which is not computed by this model 
Table 2. Set of measurements at the Obidos gauging station.

\begin{tabular}{cccccc}
\hline & $Q\left(\mathrm{~m}^{3} \mathrm{~s}^{-1}\right)$ & $L(\mathrm{~m})$ & $Z_{\mathrm{s}}(\mathrm{m})$ & $V_{\mathrm{s}}\left(\mathrm{m} \mathrm{s}^{-1}\right)$ & $I_{\mathrm{S}}\left(\mathrm{m} \mathrm{m}^{-1}\right)$ \\
\hline 1 & 191351 & 2185 & 9.41 & 1.52 & $1.798 \times 10^{-5}$ \\
2 & 107557 & 2257 & 4.64 & 1.08 & $1.15 \times 10^{-5}$ \\
3 & 195302 & 2252 & 10.31 & 1.66 & $1.81 \times 10^{-5}$ \\
4 & 206605 & 2319 & 10.30 & 1.79 & $1.81 \times 10^{-5}$ \\
5 & 192802 & 2255 & 10.22 & 1.65 & $1.81 \times 10^{-5}$ \\
6 & 169787 & 2257 & 8.25 & 1.52 & $1.60 \times 10^{-5}$ \\
7 & 183388 & 2288 & 8.29 & 1.59 & $1.60 \times 10^{-5}$ \\
8 & 175700 & 2295 & 8.35 & 1.52 & $1.62 \times 10^{-5}$ \\
9 & 94901 & 2230 & 3.76 & 0.95 & $9.86 \times 10^{-6}$ \\
10 & 94421 & 2278 & 3.71 & 0.93 & $9.71 \times 10^{-6}$ \\
11 & 86160 & 2273 & 3.49 & 0.82 & $9.86 \times 10^{-6}$ \\
12 & 108697 & 2272 & 4.60 & 1.05 & $1.11 \times 10^{-5}$ \\
13 & 177785 & 2295 & 8.76 & 1.59 & $1.61 \times 10^{-5}$ \\
14 & 173855 & 2138 & 9.15 & 1.64 & $1.57 \times 10^{-5}$ \\
15 & 83341 & 2272 & 3.57 & 0.90 & $8.93 \times 10^{-6}$ \\
16 & 132504 & 2303 & 5.93 & 1.23 & $1.36 \times 10^{-5}$ \\
17 & 94056 & 2241 & 3.92 & 0.87 & $1.00 \times 10^{-5}$ \\
18 & 116069 & 2440 & 4.45 & 1.01 & $1.07 \times 10^{-5}$ \\
19 & 163564 & 2422 & 7.86 & 1.41 & $1.31 \times 10^{-5}$ \\
20 & 176191 & 2436 & 7.92 & 1.41 & $1.65 \times 10^{-5}$ \\
21 & 176842 & 2591 & 8.73 & 1.43 & $1.55 \times 10^{-5}$ \\
\hline & & & & &
\end{tabular}

is the surface slope. We ran the model on a virtual $10 \mathrm{~km}$ reach and then used the Bercher (2008) method to obtain the surface slope. These data were used primarily to control the response of our method to different noise configurations (by adding random variations to one or more surface measurements) and of course to verify that the method performed well on noiseless data. The discharge estimation method was applied to the simulated dataset without adding noise to the surface variables. The dataset was generated on a river geometry similar to the Rhone river: $300 \mathrm{~m}$ width, the discharge varying between 1000 and $2000 \mathrm{~m}^{3} \mathrm{~s}^{-1}$ and downstream water level condition varying between $16.56 \mathrm{~m}$ and $18 \mathrm{~m}$.

\section{Results and discussion}

All the results presented here have been obtained by using the datasets as if they came from EO measurements. We processed only the surface measurements $\left(Z_{i}, V_{\mathrm{s} i}, I_{\mathrm{s} i}\right)_{(i=1 \cdots N)}$, then compared the results to the corresponding discharge measurements.

To avoid possible confusion, we should explain how the same dataset was separated into two parts for the purpose of the analysis. Two-thirds of the data points were randomly selected and were used to estimate the hydraulic parameters $(K$ and $Z_{\mathrm{b}}$ ). For each surface measurement, we then computed the corresponding discharge by using the estimated parameters. Finally, this computed estimate was compared to the measured discharge.

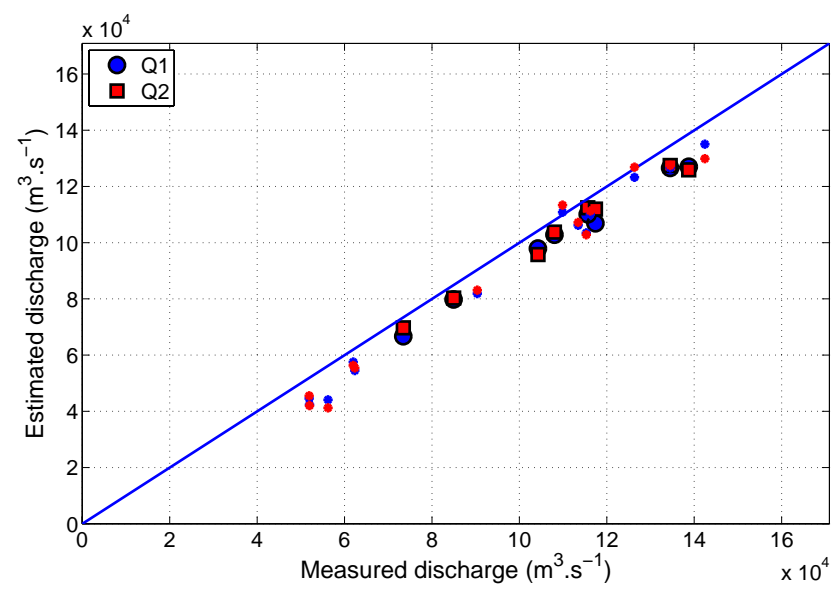

Fig. 1. Comparison of the estimated discharge using Eqs. (8) and (9) and the ADCP discharge measurements at Manacapuru gauging station. The calibration points are plotted with blue and red stars for $Q_{1}$ and $Q_{2}$ respectively.

\subsection{Model results on ADCP data}

In our first analysis, the model was applied to the Manacapuru and Obidos datasets.

\subsubsection{Model results from the Manacapuru station dataset}

The estimate based on the Manacapuru station data was quite satisfactory (Fig. 1).

The mean relative error of the estimate was $5.98 \%$ with a standard deviation of 0.052 . The estimated river bed elevation $(-3.86 \mathrm{~m})$ was consistent with the value computed from ADCP data $(-5.63 \mathrm{~m})$ in view of the depth of the river at this station (between 17 and $27 \mathrm{~m}$ ).

A comparison of the estimated Strickler coefficient (36.98) is more difficult to obtain, because we do not have direct measurements of this parameter. However, we calculated the coefficient of each ADCP measurement using Eq. (9). The estimate and the computed coefficient (34.24) obtained using this calculation were consistent.

\subsubsection{Model results from the Obidos station dataset}

Although the results for the Manacapuru dataset were satisfactory, the process could not successfully estimate the hydraulic parameters using the Obidos dataset. The estimated river bed elevation was $-4.67 \mathrm{~m}$ whereas ADCP measurements gave a mean river bed elevation of $-39.46 \mathrm{~m}$. Likewise, we estimated a value of 65.03 for the Strickler parameter, whereas we found 28.48 using the ADCP data. Accordingly, it is not surprising that the estimated discharge represented approximately $25 \%$ of the actual discharge (Fig. 2). 


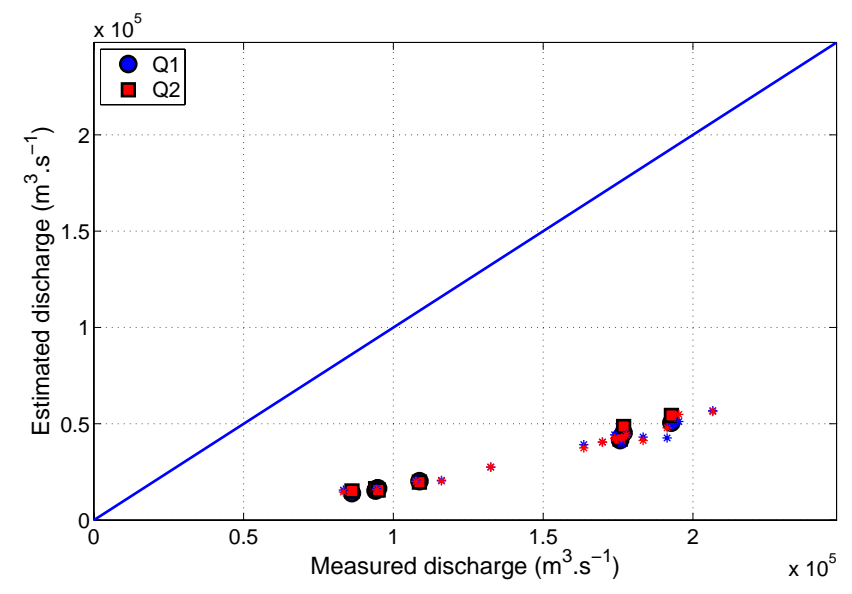

Fig. 2. Comparison of the estimated discharge using Eqs. (8) and (9) and the ADCP discharge measurements at Obidos gauging station. The calibration points are plotted with blue and red stars for $Q_{1}$ and $Q_{2}$ respectively

However, even if the discharge estimates were not as expected for the Obidos dataset, the two equations $Q_{1}$ and $Q_{2}$ appeared to give similar results.

The similar results for discharge estimation with $Q_{1}$ and $Q_{2}$ were expected, as the cost function and the estimated discharge calculation are made using the same equations. However, the minimization criterion is equivalent to the root mean square error of the water elevation equation obtained from $Q_{1}$ and $Q_{2}$. Therefore it does not directly result from these equations. It could occur that measurement inaccuracies, on the surface velocity for example, should lead to two different results on $Q_{1}$ and $Q_{2}$. However, such a situation seems unlikely in natural conditions.

The estimation error that we observed may have resulted from one or more assumptions.

\subsection{Calibration and validation set selection}

All the presented results were obtained on one random calibration and validation dataset. For both sites, we repeated the calibration operation ten thousand times to test the robustness of the calibration dataset selection. Parameter and discharge estimations remained consistent over the 10000 trials. For the Manacapuru dataset, the mean river bed elevation was $3.93 \mathrm{~m}$ (with a standard-deviation of $1.04 \mathrm{~m}$ ) whereas the mean Strickler coefcient was 35.00 (with a standarddeviation of 1.11). The mean discharge estimation error was $7.24 \%$ (with a standard-deviation of 0.04 ), a touch higher than the error we presented for one dataset. For Obidos the results also remained consistent with a mean bed elevation of $4.73 \mathrm{~m}$ (standard-deviation: $0.70 \mathrm{~m}$ ) and a mean Strickler coefficient of 61.52 (standard-deviation: 2.49 ). The standard deviation of the discharge estimation error was $0.01 \%$.

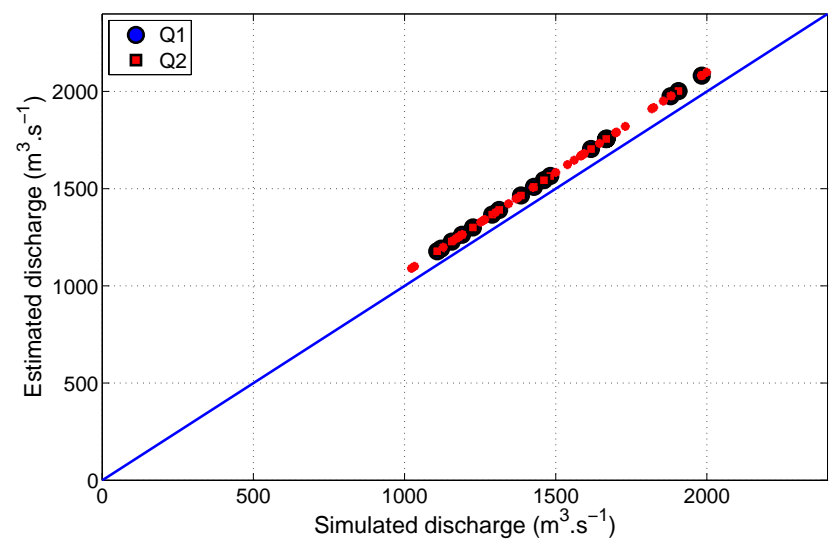

Fig. 3. Representation of the estimated discharge using Eqs. (8) and (9) against simulated discharge measurements. The calibration points are plotted with blue and red stars for $Q_{1}$ and $Q_{2}$ respectively

For the simulated dataset, as all the virtual measurements are perfectly aligned, the different calibration sets led to the same results in all cases.

\subsection{Model results on simulated data}

It appears from Fig. 3 that the method slightly overestimated the discharge based on noiseless data. The mean relative error was $6 \%$ with a standard deviation of 0.004 .

In fact, these simulated data fit the first discharge expression $Q_{1}$ (Eq. 8) perfectly, but not the second expression $Q_{2}$ (Eq. 9). Because we fixed the Strickler parameter $K$ and the river bed elevation $Z_{\mathrm{b}}$ in the hydrodynamic model, the surface variable, and more precisely the surface slope, was the only possible error source. Indeed, the water elevation $Z$ is shared between the $Q_{1}$ and $Q_{2}$ expressions, the surface velocity is only present in $Q_{1}$ and the surface slope in $Q_{2}$.

If we calculated a surface slope fitting the uniform equation Eq. (9) instead of the Bercher (2008) method, a difference appeared between the two slope values. The calculated slope was $6 \%$ less than the estimated one. This result explains the overestimation of the discharge.

\subsection{Results of the Bjerklie models and comparison with the proposed model}

Finally, we applied the five statistical models described earlier in Sect. 2 to the Manacapuru dataset, the Obidos dataset and the simulated dataset.

Figures 4, 5 and 6 represent the estimated discharge using Bjerklies model and our model.

Our model is represented by the blue circles and red squares, as in the previous figures. The five statistical models are represented by green stars, blue crosses, brown diamonds, purple triangles and grey pentagrams, respectively. Finally, the blue line represents the ideal case. 


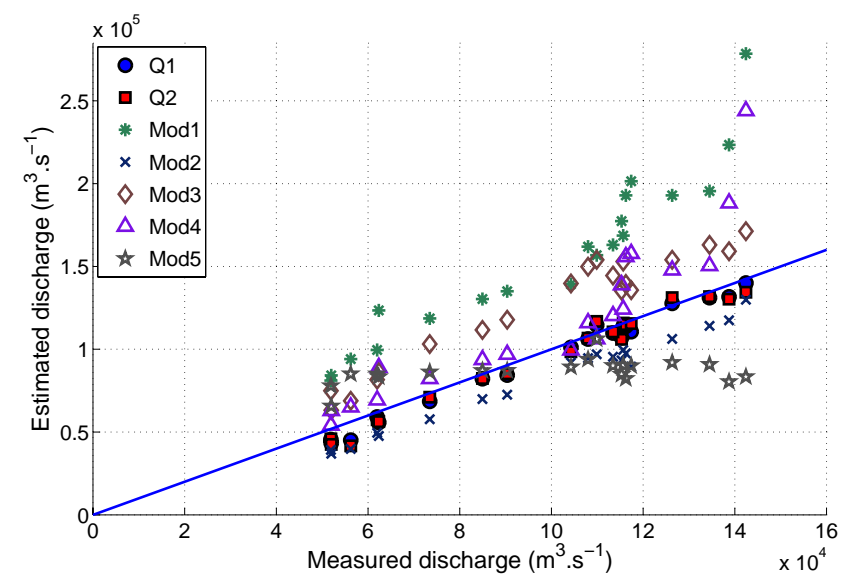

Fig. 4. Comparison of the estimated discharge with the ADCP discharge measurements for the Manacapuru dataset.

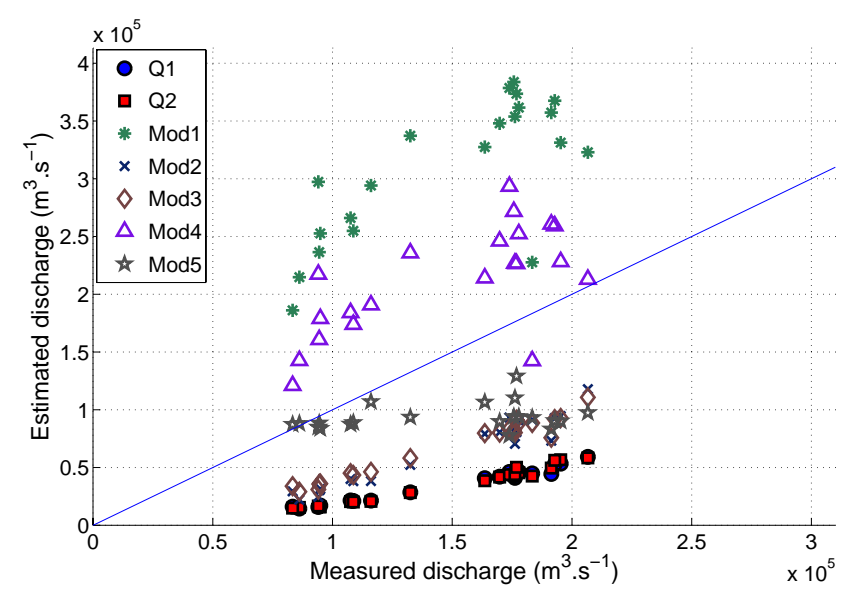

Fig. 5. Comparison of the estimated discharge with the ADCP discharge measurements for the Obidos dataset.

At first glance, we reach the same conclusion as Bjerklie et al. (2005). The fifth model appeared to give poor results. In every case, the estimated discharge remained quasi-constant, whatever the value taken by the measured discharge.

The other models gave different results that agreed in some cases with the results obtained from our method.

With the simulated data, models (1) and (4) gave results similar to those of our model. They overestimated the discharge with a mean relative error of $13 \%$ and $5 \%$, respectively.

The second model, with a mean relative error of $18 \%$, yielded the best results for the Manacapuru dataset. The fourth model was quite good as well (mean relative error of $19 \%$ ). However, for values of discharge over $140000 \mathrm{~m}^{3} \mathrm{~s}^{-1}$, it dramatically overestimated the discharge. This result is not satisfying, but it may be due to the fact that we did not recalibrate the equations.

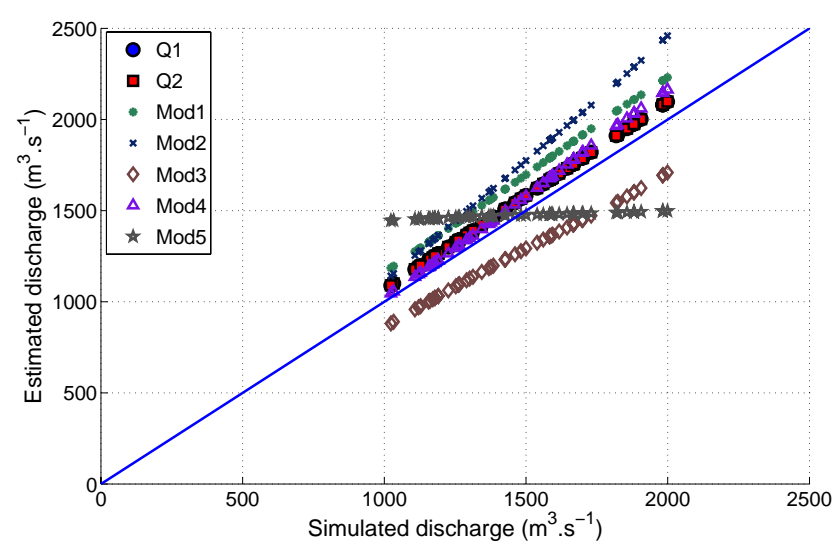

Fig. 6. Comparison of the estimated discharge with simulated discharge measurements.

Finally, for the Obidos dataset, none of the five models gave results that were really any better than the results obtained from our own model. The second and the third models underestimated the discharge by half, but they exhibited good coherence (respective standard deviations 0.09 and 0.06), whereas the first and fourth models overestimated the discharge by a factor of two, and the dispersion of the estimates was very large (standard deviations of 0.42 and 0.29 , respectively).

It seems impossible to determine from these results which model would be suitable for estimating a river discharge in all cases. Nevertheless, the fourth model might be the most promising, and calibration using a larger set of river measurements should improve its performance. Nevertheless, this model requires depth information for the discharge estimation.

\subsection{Sources of estimation error}

The results of all the analyses indicate that problems of some kind are associated with the Obidos dataset. This dataset gives poor results, no matter which method is applied. These problems might have arisen because one or more limiting assumptions does not apply to the gauging station measurements.

In the next sections we outline the main sources of error that can be associated with our method. This description is qualitative rather than quantitative: as the method has been tested using data from only 2 different gauging stations, we cannot assess the relative importance of the different sources of error. The simulated datasets allow a verification of the method, but such a simple 1D model cannot be used to validate the method. More datasets would be needed to complete this study. 

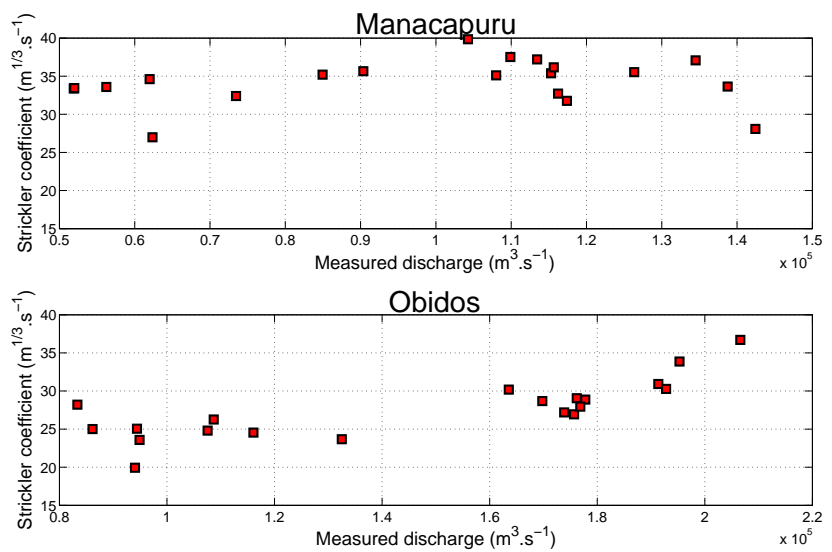

Fig. 7. Variation of the Strickler coefficient with the estimated discharge for the Manacapuru station dataset (top) and the Obidos station dataset (bottom).

\subsubsection{Fixed $\alpha$}

This first possible source of error has been discussed in Sect. 3.2. All our data are consistent with this assumption, so it cannot explain the estimation errors.

\subsubsection{Fixed Strickler coefficient $K$}

Unfortunately, this coefficient cannot be measured directly, so this assumption cannot be checked. As explained in Sect. 4.1.1, the values of the Strickler coefficient $K$ have been computed using the ADCP measurements and the discharge equations, Eq. (9) defined previously.

Both stations appeared to exhibit a varying Strickler coefficient (Fig. 7)

with a similar standard deviation (2.89 for Obidos and 2.23 for Manacapuru). It is therefore impossible to determine whether the variation of the Strickler coefficient is the source of the problem with the Obidos data. However, it is interesting to note the correlation $\left(r^{2}=0.86\right)$ between the discharge and the values of the Strickler coefficient for the Obidos data. This correlation was not found for the Manacapuru dataset but we cannot conclude whether this affects the estimates of the discharge substantially or not. If we estimate the discharge on the Obidos station dataset, using the mean computed Strickler coefficient $(K=28.48)$ and the mean measured bed elevation $\left(Z_{b}=-39.46 \mathrm{~m}\right)$, the results are satisfactory. These estimates had a mean relative error of 0.09 and a standard-deviation of 0.05 .

We can note that a fixed mean $K$ parameter yields very good estimates of the discharge. However, the calculation of this coefficient requires information on the surface slope, and we therefore doubt that this approach can yield precise results (Eq. 9, Sects. 4.5.4, 4.5.5). Accordingly, no conclusions can be reached about the possible role of this source of estimation error.

\subsubsection{Variability of $Z_{b}$}

The movements of the local topography of the river bed are another possible source of error. We assumed that the river bed elevation was constant and equal to the water elevation $Z$ minus the mean depth $Y$. In fact, the Amazon River bed is characterised by a massive amount of dune movement. Consequently, depending on where and when the ADCP measurements were made, the measured bed level might vary greatly at a single gauging station.

At Obidos station, the difference between the highest and lowest bed level found from the ADCP measurements is $15.66 \mathrm{~m}$. The mean bed level is $-39.46 \mathrm{~m}$, with a standard deviation of $3.54 \mathrm{~m}$. At Manacapuru station, the variation of the bed level is likewise noticeable. However, the amplitude of this variation is $7.10 \mathrm{~m}$. The mean river bed elevation is $-5.63 \mathrm{~m}$, with a standard deviation of $1.76 \mathrm{~m}$.

We can observe that both the total amplitude of bed level variations and the standard deviation of the bed level for the Manacapuru dataset are half as large as the corresponding values for the Obidos data. These are roughly equivalent, however, if compared to the mean river depth: $23.54 \mathrm{~m}$ for Manacapuru and $46.40 \mathrm{~m}$ for Obidos. If the discharge is calculated using Eq. (8) with the mean measured bed level, the results for the Obidos data become satisfactory (mean relative error $=0.13$ with a standard deviation $=0.04)$, and are equivalent to the results for the Manacapuru data. Thus, dune movements do not seem to explain the problem with the Obidos estimates.

\subsubsection{Uniform hypothesis}

This last hypothesis is clearly not valid. Previously, we assumed that the water surface slope, the linear energy slope and the bed slope were all equal $\left(I_{\mathrm{s}}=I_{\mathrm{b}}=S\right)$. The bed slope is the ground and is therefore not supposed to move, but the surface slope varies over time.

The surface slope varies for both gauging station datasets as well as in the simulated dataset. The model still applies to Manacapuru and on the simulated dataset, but not rigorously. Nevertheless, the estimation method works well on these datasets. This difference might result from the amplitude of the variation in the slope. At Obidos station, the mean slope is $1.39 \times 10^{-5} \mathrm{~m} \mathrm{~m}^{-1}$ with a standard deviation of $3.27 \times 10^{-6}$, whereas the Manacapuru station dataset has a mean slope of $2.09 \times 10^{-5} \mathrm{~m} \mathrm{~m}^{-1}$ with a standard deviation of $2.57 \times 10^{-6}$. This value of the standard deviation is markedly less despite the higher mean value of the Manacapuru slope. This difference in the variation in the amplitude of the slope might explain, at least in part, the results that we obtained with the estimation model.

Another important point about the surface slope is that it is calculated from the derivative of a function fitted to a water level series between four gauging stations surrounding, upstream and downstream, the considered station. We have 
considered the scale of the slope values, but the precision of these estimates could also be viewed as a possible source of error. This issue can only be resolved through verification based on ground truthing. Finally, Obidos is the first gauging station under tidal influence (Callède et al., 2000). Any station downstream from Obidos would exhibit even more tidal influence. Consequently, the method for the estimation of the slope might be biased by the tides. This factor could result in incorrect values of the slope.

\subsubsection{Tidal influence}

The tidal influence might jeopardise the estimation of the slope. It is likely to be even more important for the water elevation and the discharge.

Kosuth et al. (2009) and Callède et al. (2000) measured an $8 \mathrm{~cm}$ variation in the water level at Obidos station, a variation of nearly $10 \%$ of the discharge. Considering that most of the section in which flow occurs is below sea level, this variation in the discharge might reflect great differences in the vertical profile of the velocity during different tidal phases. If both the velocity and the surface slope are widely influenced by the tides, this factor would explain the incorrect estimates of the hydraulic parameters.

\section{Conclusion}

We proposed a new method for estimating river discharge, based on a set of limiting assumptions about river flow and a linear least squares approach to estimation of the hydraulic parameters. Given synchronous measurements of the surface hydraulic variables $\left(Z_{i}, V_{\mathrm{s} i}, I_{\mathrm{s} i}\right)_{(i=1 \cdots N)}$, this method should make it possible to estimate the discharge at a given station on any river. The method requires an initial set of measurements to estimate the hydraulic parameters $Z_{\mathrm{b}}$ and $K$. It then estimates the discharge corresponding to each new set of surface variable measurements.

This method was developed and tested primarily on data from two Amazon gauging stations (Manacapuru and Obidos) and on simulated data. The method appears promising in view of the results obtained for the Manacapuru and simulated datasets and in view of the fact that the relative error in the discharge estimates was under $10 \%$. However, the incorrect estimation of the discharge for the Obidos dataset remains a problem. We have explored and discussed many possible sources that might account for this error. As long as we cannot verify the accuracy of our estimation of the surface slope or the impact of the tidal influence on the estimates, we cannot isolate the source of this error with certainty. Our approach provides results similar to those obtained from the best of the Bjerklie models. However, the best of these models require bathymetric information, and this information cannot be obtained, nowadays, by using EO techniques. Because our aim is to obtain estimates that do not use ground measurements, the requirement for bathymetric information is a problem.

To solve the problem of the varying surface slope, the development of an adaptation of this method to a non-uniform flow configuration is continuing. Furthermore, ground validation of the water surface slope should be performed to validate the estimation method.

Acknowledgements. The authors wish to thank the editor and the anonymous reviewers whose constructive remarks led to a significant improvement of the manuscript. We are also grateful to Dr Claire Marsden for the english revision of our manuscript. This work was supported by the French space agency "Centre national d'études spatiales" (CNES) and benefited from a grant by CNES and a grant by PNTS "Programme national de télédétection spatiale".

Edited by: W. Wagner

\section{References}

Alsdorf, D., Birkett, C., Dunne, T., Melack, J., and Hess, L.: Water level changes in a large Amazon lake measured with spaceborne radar interferometry and altimetry, Geophys. Res. Lett., 28, 2671-2674, doi:10.1029/2001GL012962, 2001.

Alsdorf, D. E., Rodríguez, E., and Lettenmaier, D. P.: Measuring surface water from space, Rev. Geophys, 45, 1-24, 2007.

Baume, J. P., Malaterre, P. O., Belaud, G., and Guennec, B. L.: SIC: A 1D hydrodynamic model for river and irrigation canal modeling and regulation, Métodos Numéricos em Recursos Hidricos, 7, 1-81, 2005.

Bercher, N.: Precision de l'altimetrie satellitaire radar sur les cours d'eau: Developpement d'une méthode standard de quantification de la qualité des produits alti-hydrologiques et applications, Ph.D. thesis, Agro Paris Tech, Montpellier, 2008.

Bjerklie, D. M., Dingman, S. L., Vorosmarty, C. J., Bolster, C. H., and Congalton, R. G.: Evaluating the potential for measuring river discharge from space, J. Hydrol., 278, 17-38, 2003.

Bjerklie, D. M., Moller, D., Smith, L. C., and Dingman, S. L.: Estimating discharge in rivers using remotely sensed hydraulic information, J. Hydrol., 309, 191-209, 2005.

Callède, J., Kosuth, P., Guyot, J., and Guimaraes, V. S.: Discharge determination by Acoustic Doppler Current Profilers (ADCP): a moving bottom error correction method and its application on the river Amazon at Obidos, Journal des Sciences Hydrologiques, 45, 911-924, 2000.

Coe, M. T. and Birkett, C. M.: Calculation of River Discharge and Prediction of Lake Height from Satellite Radar Altimetry: Example for the Lake Chad Basin, AGU Fall Meeting Abstracts, 22, 05, 2004.

Contractor, D. N. and Schuurmans, W.: Informed use and potential pitfalls of canal models, J. Irrig. Drain. E., 119, 663-672, 1993.

Costa, J. E., Spicer, K. R., Cheng, R. T., Haeni, F. P., Melcher, N. B., Thurman, E. M., Plant, W. J., and Keller, W. C.: Measuring stream discharge by non-contact methods: A proof-of-concept experiment, Geophys. Res. Lett., 27, 553-556, 2000.

Durand, M., Rodriguez, E., Alsdorf, D. E., and Trigg, M.: Estimating River Depth From Remote Sensing Swath Interferometry 
Measurements of River Height, Slope, and Width, IEEE Journal on Selected Topics in Applied Earth Observations and Remote Sensing, 3, 20-31, 2010.

Franchini, M., Lamberti, P., and Di Giammarco, P.: Rating curve estimation using local stages, upstream discharge data and a simplified hydraulic model, Hydrol. Earth Syst. Sci., 3, 541-548, doi:10.5194/hess-3-541-1999, 1999.

Gordon, R. L.: Acoustic Measurement of River Discharge, Journal of Hydraulic Engineering, 115, 925-936, doi:10.1061/(ASCE)0733-9429(1989)115:7(925), 1989.

Kosuth, P., Blitzkow, D., and Cochonneau, G.: Etablissement d'un référentiel altimétrique sur le bassin amazonien par altimétrie satellitaire radar (Topex Poseidon), p. 8, Venise, ITA, 2006.

Kosuth, P., Callède, J., Laraque, A., Filizola, N., Guyot, J. L., Seyler, P., Fritsch, J. M., and aes, V. G.: Sea-tide effects on flows in the lower reaches of the Amazon River, Hydrol. Process., 23, 3141-3150, doi:10.1002/hyp.7387, 2009.

LeFavour, G. and Alsdorf, D.: Water slope and discharge in the Amazon River estimated using the shuttle radar topography mission digital elevation model, Geophys. Res. Lett., 32, 5 pp., doi:10.1029/2005GL023836, 2005.

Macklin, J. T., Ferrier, G., Neill, S., and Folkard, G. C.: Alongtrack interferometry (ATI) observations of currents and fronts in the Tay estuary, Scotland, EARSeL eProceedings, 3, 179-190, 2004.

Melcher, N. B., Costa, J. E., Haeni, F. P., Cheng, R. T., Thurman, E. M., Buursink, M., Spicer, K. R., Hayes, E., Plant, W. J., Keller, W. C., and Hayes, K.: River discharge measurements by using helicopter-mounted radar, Geophys. Res. Lett., 29, 41-1, 2002.

Morlock, S. E.: Evaluation of acoustic Doppler current profiler measurements of river discharge, US Geological Survey, Water Resources Investigations Report, 95-4218, 1996.

Oberg, K. and Mueller, D. S.: Validation of Streamflow Measurements Made with Acoustic Doppler Current Profilers, J. Hydraul. Eng., 133, 1421-1432, doi:10.1061/(ASCE)07339429(2007)133:12(1421), 2007.

Rantz, S. E. S. E.: Measurement and computation of streamflow, Geological Survey water-supply paper.; 2175, United States Government Printing Office, Washington, DC, 1982.
Romeiser, R., Runge, H., Suchandt, S., Sprenger, J., Weilbeer, H., Sohrmann, A., and Stammer, D.: Current measurements in rivers by spaceborne along-track InSAR, IEEE Trans. Geosci. Remote Sens., 45, 4019-4031, 2007.

Smith, L. C., Isacks, B. L., Forster, R. R., Bloom, A. L., and Preuss, I.: Estimation of discharge from braided glacial rivers using ERS 1 synthetic aperture radar: First results, Water Resour. Res., 31, 1325-1329, 1995.

Smith, L. C., Isacks, B. L., Bloom, A. L., and Murray, A. B.: Estimation of discharge from three braided rivers using synthetic aperture radar satellite imagery: Potential application to ungaged basins, Water Resour. Res., 32, 2021-2034, 1996.

Sun, W., Ishidaira, H., and Bastola, S.: Towards improving river discharge estimation in ungauged basins: calibration of rainfallrunoff models based on satellite observations of river flow width at basin outlet, http://adsabs.harvard.edu//abs/2010HESSD...7. 3803S, 2010.

Thompson, D., Graber, H., and Carande, R.: Measurements of ocean currents with SAR interferometry and HF radar, in: Geoscience and Remote Sensing Symposium, 1994. IGARSS '94. Surface and Atmospheric Remote Sensing: Technologies, Data Analysis and Interpretation, International, vol. 4, 2020-2022, doi:10.1109/IGARSS.1994.399641, 1994.

Wang, C. K. and Philpot, W. D.: Using airborne bathymetric lidar to detect bottom type variation in shallow waters, Remote Sens. Environ., 106, 123-135, 2007.

Xu, K., Zhang, J., Watanabe, M., and Sun, C.: Estimating river discharge from very high-resolution satellite data: a case study in the Yangtze River, China, Hydrol. Process., 18, 1927-1939, doi:10.1002/hyp.1458, 2004.

Zhang, J., Xu, K., Watanabe, M., Yang, Y., and Chen, X.: Estimation of river discharge from non-trapezoidal open channel using QuickBird-2 satellite imagery/Utilisation des images satellites de Quickbird-2 pour le calcul des débits fluviaux en chenaux ouverts non-trapézoidaux, Hydrolog. Sci. J., 49, 247-260, 2004. 